Advances in Geosciences, 3, 19-22, 2005

SRef-ID: $1680-7359 /$ adgeo/2005-3-19

European Geosciences Union

(c) 2005 Author(s). This work is licensed

under a Creative Commons License.

\title{
AVISO user service, at the crossroads between user information, outreach and education
}

\author{
V. Rosmorduc \\ CLS/AVISO, 8-10 rue Hermes, 31526 Ramonville StAgne, France
}

Received: 13 August 2004 - Revised: 20 January 2005 - Accepted: 21 January 2005 - Published: 16 June 2005

\begin{abstract}
Initially set up to distribute Topex/Poseidon ocean altimetry satellite data, AVISO user service has been the link between the Topex/Poseidon and Jason-1 projects, users and the general public. The service has continually broadened the scope of its activities, forging close ties with users to achieve efficient dissemination of general, technical, and scientific information. Such a synergy between user services and outreach has many advantages, both for users and for public outreach, including educational ones.
\end{abstract}

\section{AVISO}

AVISO stands for Archiving, Validation and Interpretation of Satellite Oceanographic data. It was set up in 1992 to process, archive and distribute data from the NASA/CNES ocean radar altimetry satellite Topex/Poseidon (T/P). Now, twelve years later, AVISO user service's activities encompass:

- Operational distribution of Topex/Poseidon, Jason-1 and Envisat Geophysical Data Records (GDRs)

- Distribution of high-level altimetry products, including operational distribution of near-real time products

- A catalogue of altimetry, orbit determination and precise location products

- Outreach for ocean altimetry, orbit determination and precise location activities.

Since the launch of Topex/Poseidon in 1992, AVISO has worked hard to foster close collaboration between project teams, data users and to develop information to the general public. Since the main responsibility of AVISO is data distribution, outreach to potential users has always been part of the service. A Newsletter was published as early as 1992,

Correspondence to: V. Rosmorduc

(vinca.rosmorduc@cls.fr) and T/P first results leaflets were released soon after the commissioning phase; such outreach material has continuously been released during those years, either by AVISO and CNES alone, or in cooperation with the American side of the project. Indeed, one of the first actions AVISO undertook was to develop closer coordination with JPL and multiple science teams in order to define and take part in Topex/Poseidon promotional activities, in particular through the Outreach sub-group created within the Science Working Team (SWT). All information, whether on data or outreach are updated on the AVISO website http://www.AVISO.oceanobs.com, in both French and English (a Spanish section is also available, for basic information).

\section{User information}

AVISO users evolved along the years: first users were PIs/Co-Is of the T/P mission, i.e. mostly altimetry experts or at least physical oceanographers with a working knowledge of altimetry; now new ones are mostly neophytes (Rosmorduc and Picot, 2004). The change was also from programmers, i.e. people able to write themselves a program in Fortran or C, to software users, in a large part. Another change is that even physical oceanographers are not anymore specialized in a specific observation technique. They are now using every available observation system and also model outputs to observe and study a class of phenomena. Thus they do not wish to delve too deeply in the characteristics of each technique, and expect to benefit from "standardized" dataset formats, highly processed data, and clear, to-the-point, information. Users now are not only physical oceanographers - we are reaching a much wider audience, including biologists, chemical oceanographers, climatologists, meteorologists, end-users, college students and even school children! Geographic location of users has also diversified, with more and more developing countries joining the altimetry users. With the broader audience comes the need for more and more "basic" information since the new laboratories getting 


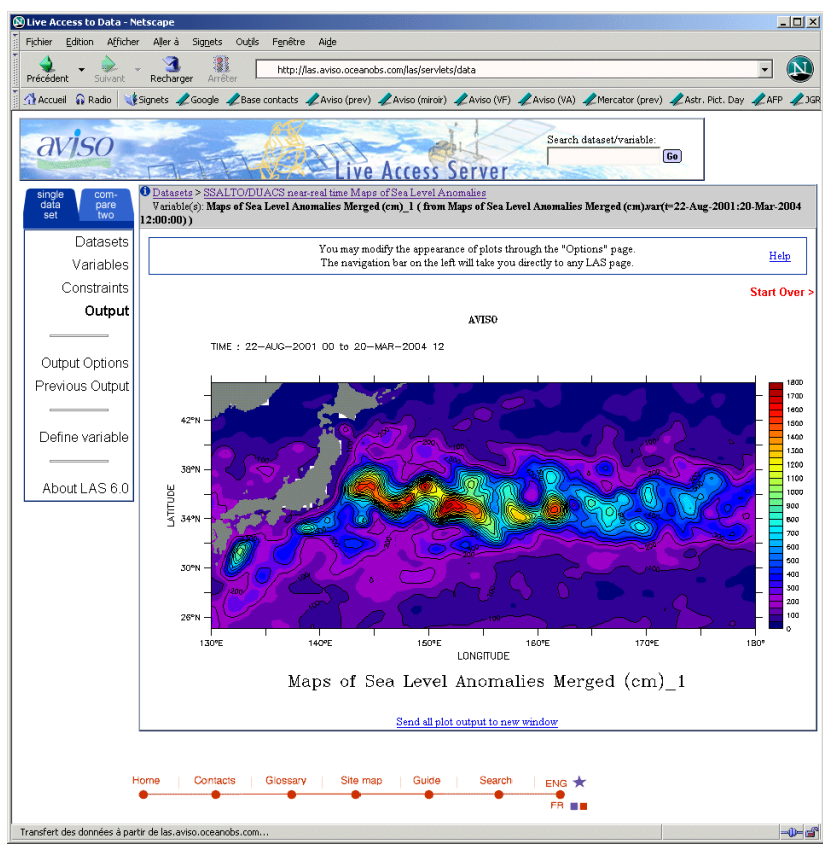

Fig. 1. The Live Access Server is a data retrieval and visualization tool, that allows even non-specialists to plot complex maps (here variance of sea level anomalies over the Kuroshio).

involved have not always the background in altimetry data processing that the previous users had.

When AVISO began distributing its data in 1993, CDROMs were a new thing in the laboratories, so much so that the space agencies involved in Topex/Poseidon (NASA and CNES) decided to buy a CD Rom driver to their PIs. You then had to explain how to mount the CD driver when using either the VMS or Unix operating system. CD-ROMs soon became standard, now substituted by DVDs providing much higher storage capacity. Online distribution became possible around 1995, and feasible (at least for developed countries) in 1999-2000 for important amounts of data. Now, webbased distribution, real use of the web to transport and/or visualize data, is developing. Interactive tools for data management have now reached a maturity that allows a center like AVISO to use them, with tools like the "Live Access Server" that makes it possible for web visitors to draw their own maps (Fig. 1). Thus, data "use" is no more exclusively for scientists or engineers who can write a computer program. Students or even casual users can use such tools, so they must be informed of what can be done with those data.

It is essential to let the potential users become aware that the data exist. Internet plays a major role in this respect. Indeed, whereas in the past you had to know about a data distribution center before you contacted it, now web sites enable would-be users - to search for themselves where the data they need exist, to have complete, immediate information about the data, and to compare formats and services, etc. Thus, data distribution web sites must be complete, with much information if they wish to have a chance of being found. And Internet is also playing the other way round: users can interact much more easily via e-mail than they previously could by "snail-mail". So more and more questions reach the AVISO user service, from new and old users, but also from students (high school or undergraduate as well as $\mathrm{PhD}$ ). We try to answer all of them as well as possible, and enhance the web site http://www.AVISO.oceanobs.com to give a more and more complete view of altimetry applications and techniques - and that is what is called outreach, isn't it?

Thus user information is coming closer to "general public" outreach, with a broader audience that needs simple explanations, easy-to-use tools, and "don't hesitate to ask questions" to the helpdesk.

\section{Outreach}

The AVISO user service is closely linked to the outreach team, allowing strong interactions. Links between users and outreach is not only one way, by informing the users. User feedback gives information that may become outreach "stories" - like new research results, new applications, etc. - and also helps to enhance outreach documentation that is available and to make applications and science results known. Users need to promote their work - and "what for" is an important issue for outreach and education. Outreach is a means of explaining the data, what they allow, to ensure that altimetry data and information are used, and to attract attention on the technique and its usefulness in everyday life. One of the side aspects of having non-specialists asking questions is that we can know what are the issues the public is sensitive to - and thus develop information on the appropriate subjects. With the future of altimetry in discussion today, outreach is more necessary than ever: since users need long-term and continuous datasets, this need must be advertised to ensure continuity of altimetry missions and information products. It is important that people understand the role of altimetry in conjunction with other instruments in providing information about our oceans and climate, to stimulate interest in ocean science and the environment. This understanding ensures that scientists, marine operators and educators are able to use the data and information if appropriate to their work.

From the first newsletter - a yearly publication - and "quick look" leaflets, AVISO has considerably broadened its outreach activities and outputs (Fig. 2):

- Hard copy material: posters, publications, newsletter, leaflets, lithographs

- New technologies: CD-ROMs, easy-to-use data, easyto-access data, web site, on-line newsletter

- Human contacts: Summer schools, science, applications and education conferences, classroom activities, teacher workshops, user desk

- Media and museums: Interactive exhibits, press articles, videos. 


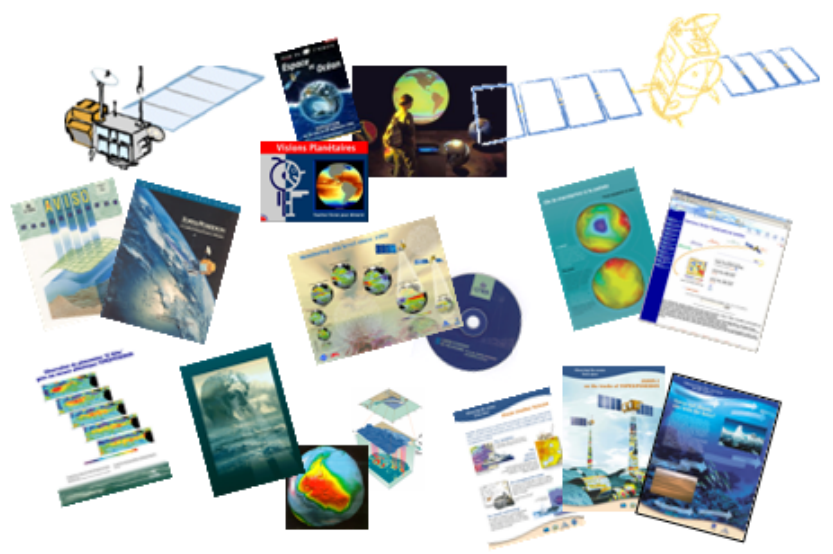

Fig. 2. A potpourri of AVISO outreach realization or participation between 1992 and 2002.

Several series of fact sheets have been published throughout the mission. The project web site, rolled out in 1995, has progressively added new features for users, including an online product catalog, as well as information for the wider audience interested in Earth sciences and oceanography. It is now the major medium for outreach, continuously updated, with news, new information and updated features.

Outreach has many possible audiences, e.g., the general public, potential and current users, scientists, and decisionmakers, students and professors, children, teachers among others. The last ones are a link toward Education, especially with the education of teachers and professors: they need outreach to be aware of what exists. Most of the information available from AVISO, except for the technical aspects of data processing and use, is at least understandable by nonspecialists with a general science background - undergraduate students.

\section{Education}

AVISO is not directly participating to educational activities, except by the outreach material available that can be used, by answering high-school student questions, sending them documentation, links, references or simply information. However, we are in close contact with the education teams, both at CNES and at JPL (Richardson and Jasnow, 2004), and with members of the Science Working Team involved - both for making new material, adapting some other (see Fig. 3), or presenting altimetry and oceanography in classrooms, at all levels. AVISO is acting as support for material and information, and as coordination, linking good wills and requests - users can also participate in school activities, at different levels, and present their job before classrooms.

CNES developed an educational project, named "Argonautica", that proposes an innovative working environment and new ways of using satellite data [Canceill et al, 2003]. It provides a framework for science teaching in schools based on the theme of oceanography, climate, and tracking of an-

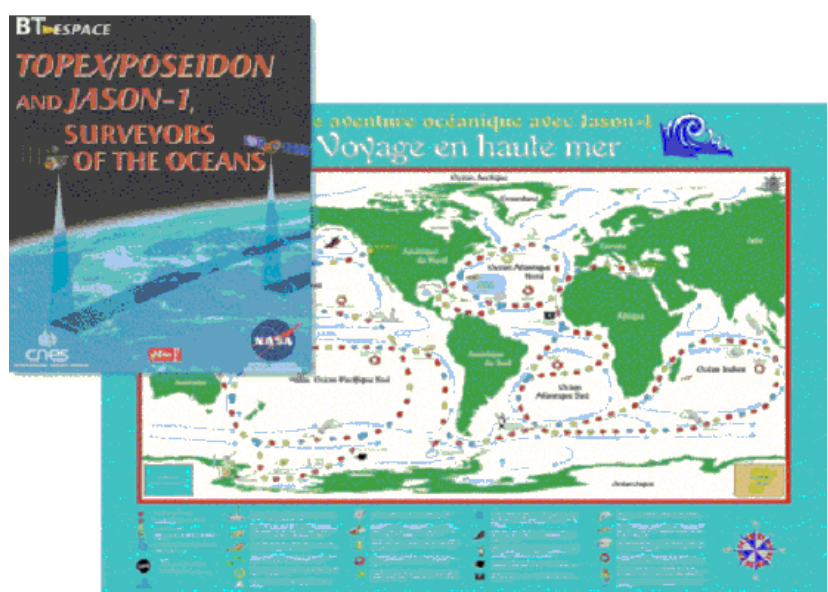

Fig. 3. A French book for children translated into English, and a JPL board game translated into French ... cooperation in Education is going both ways across the Atlantic.

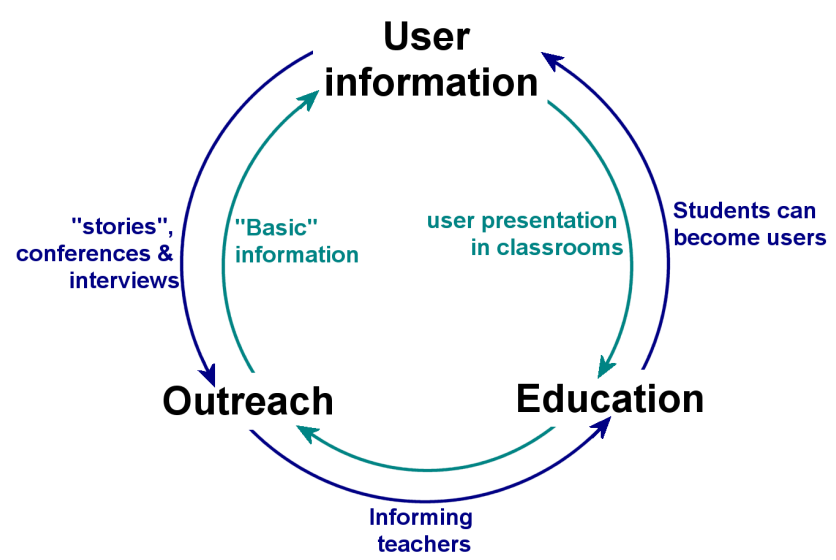

Fig. 4. User information is useful for outreach which is useful for education... and the other way round.

imals. The mantra guiding the project is: understand, experiment, and exchange. The first of these three watchwords focuses on treating kids like researchers, the second on making practical experiments the golden rule of science teaching, and the third on making science meaningful to young people. For example, classes are studying the migration of leatherback turtles in the Atlantic Ocean, comparing migration routes with temperature, salinity, current, and sea surface height outputs from the Mercator numerical ocean model. The next step will be to develop and/or adapt interactive vizualisation tools as are now used by scientists for the students, so that they not only compare existing maps, but also can draw them. Already, the AVISO Live Access Server is used by high schools students, who then become users. Back to square one (Fig. 4)! 


\section{The crossroad}

We try our best to be of use to users, helping them with the data, and promoting their work. We do hope that some of the students we reach will become users, thus expanding the altimetry applications - and needing user service; or that, at least, they will know about altimetry and support its continuity.

Thus AVISO is at the crossroad between user information, outreach and education, each enriching the other with material, information, ideas, and contacts. The AVISO web site is the main common feature: web is an irreplaceable media, versatile, easily updated, worldwide, reaching people who we didn't know would be interested, as well as experts. A major effort is put in this web site, in order to propose everyone with something of interest for him or her, and give the most complete overview of what altimetry is about.
Edited by: R. Pertzborn

Reviewed by: S. Limaye and N. Crosby

\section{References}

AVISO web site: http://www.aviso.oceanobs.com.

AVISO Live Access Server: http://las.aviso.oceanobs.com.

Canceill, P., De Staerke, D., and Picamelot, D.: Argonautica: 20000 schools over the sea, AVISO Newsletter, \#9, 17-19, 2003.

Richardson, A. and Jasnow, M.: Education and public outreach activities at JPL for ocean surface topography missions: Launching Argonautica in the U.S., AVISO Newsletter, \#10, 19-20, 2004.

Rosmorduc, V. and Picot, N.: Twelve years of user services for ocean topography users: AVISO experience and lessons learned, Ensuring the Long-Term Preservation and Adding Value to the Scientific and Technical Data (PV) 2004, ESA/ESRIN, Frascati, Italy, 2004. 